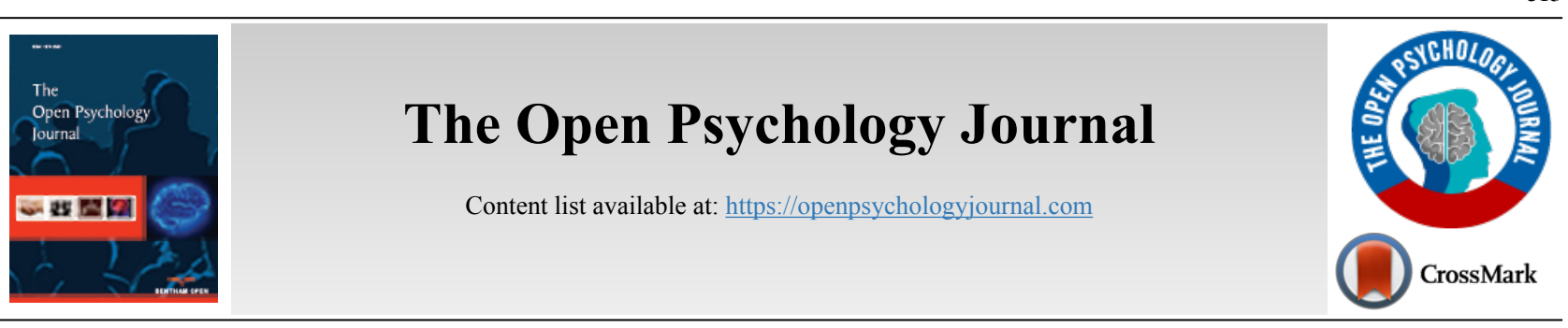

RESEARCH ARTICLE

\title{
Pre-service Teachers' Representations About Children's Learning: A Pilot Study
}

\author{
Maria L. Pedditzi ${ }^{1, *}$ and Marcello Nonnis ${ }^{1}$ \\ ${ }^{1}$ Department of Pedagogy, Psychology and Philosophy, University of Cagliari, Cagliari, Italy
}

\begin{abstract}
:
Background:

Research on teachers' representations of children's learning is currently ongoing.

Social representations are common-sense theories built and shared in everyday interactions. Their analysis can detect the possible differences between teachers' naïve beliefs and scientific learning theories.

Objective:

The objective of this pilot study is to analyse the beliefs about children's learning of a group of teachers. The beliefs will be related to the most acknowledged learning theories.
\end{abstract}

Methods:

A mixed methods research was employed to analyse 100 pre-service teachers' representations of the origins of learning and the psychological processes involved.

Results:

It emerged from the results that the teachers interviewed consider children's learning mainly as culturally acquired, which reveals the prevailing constructivist conception of learning. Many pre-service primary school teachers, however, tend to see learning as mere 'transfer of information'; many pre-service kindergarten teachers perceive learning as 'behaviour modification'. The most considered psychological aspects are 'knowledge' and 'acquisition', while emotions are barely considered.

Conclusion:

Linking implicit theories and disciplinary theories could support pre-service teachers in integrating the theory and the practice of learning so as to understand the way their models influence their educational choices.

Keywords: Social representations, Pre-service teachers, Teachers' beliefs, Teaching process, Education, School environment.

\begin{tabular}{|l|l|l|l}
\hline Article History & Received: April 07, 2020 & Revised: July 17, 2020 & Accepted: July 30, 2020
\end{tabular}

\section{INTRODUCTION}

Previous research indicates that pre-service teaching can be a difficult experience [1 - 6]. In fact, for both pre-service teachers and in-service teachers, the process of teaching and learning is influenced by numerous interacting variables (operational, contextual, relationships and personal) that interact with one another.

Among the psychological variables underlying the teach-

* Address correspondence to this author at the Department of Pedagogy, Psychology and Philosophy, University of Cagliari, via Is Mirrionis 1, 09100, Cagliari, Italy; Tel: 39070/6757519; E-mail: pedditzi@unica.it ing-learning process are teachers' beliefs about and representations of acquisition: these provide the base upon which teachers build the implicit theories on learning that, in turn, guide their teaching choices [7, 8].

In educational psychology, the study of teachers' beliefs about children's learning is an important field of study [7 - 14]. The attitude of teachers is particularly influenced by their concept of learning, of which they are often unaware, and which is strongly tied to their own training and cultural references [15]. Social representations are common sense theories built on everyday interactions and shared by a group of 
individuals [16].

Social representations, unlike prior knowledge, unknowingly influence action and form the basis for behaviour and stereotypes. Since the very beginning, research on social representations has focused on the contents of knowledge objectified and shared within specific cultural contexts [17, 18]. These studies highlighted the way people translate abstract concepts using mental images and everyday language, where scientific definitions are absorbed into different cultural belongings $[19,20]$. Social representations can then be investigated, starting from people's objectified concepts detectable in teachers' language and the most common definitions concerning the various objects of study [21, 22]. Teachers' beliefs are affected by the definitions given by the scientific community of reference [23] via disciplinary theories (Learning Theories in particular) taught in universities and training courses, but also by common-sense theories shared within groups and teacher communities and known as social representations [14].

\subsection{Scientific Theories and Implicit Theories About Learning}

Learning theories are a source of verified instructional techniques and provide the foundation for an intelligent and reasoned strategy selection [24]. In educational psychology, the main learning theories come from different perspectives: behaviourism, structuralism, cognitivism, constructivism and socio-cultural theories.

Moreover, today, other recent perspectives about learning are oriented towards specific interpersonal and emotional processes. These perspectives consider learning as a situated phenomenon, mediated by the relationship with others, emphasizing the importance of positive social, educational contexts [25 - 27]. Learning is, therefore, intended as a constructive process that takes place while the participants contribute to their "community of practices" [25]. Further recent perspectives also tend to focus on the relationship between emotions and learning, highlighting the prominent role of positive emotions in facilitating learning processes and wellbeing at school. In teacher training, the importance of bridging the gap between learning theories and educational practice is widely discussed $[28,29]$. The various methods for understanding learning bring us back to both constructions elaborated by the scientific community and transmitted through learning, and common-sense theories shared within the group and the teacher community. The major differences among teachers' shared learning theories lie in the way teachers interpret their definitions. These differences revolve around a number of key issues [24]. Schunk [30] lists some key issues and questions that help distinguish the various learning theories:

- How does learning occur?

- Which factors influence learning?

- What types of learning are best explained by the theory?

The links between disciplinary theories and implicit theories could help pre-service teachers integrate teaching theory and practice. However, even for those working in education, the answer to a direct question such as: "What do you think learning is?" can prove very difficult indeed [31].

The underlying concepts on learning can be grasped by the specific verbs teachers use when referring to it: for instance, using the verb 'to learn' as a synonym of 'to assimilate', 'to internalise' or 'to memorise' indicates that learning is understood as a process of receiving, sorting and acquiring content. Teachers' representations of learning can be investigated via the analysis of teachers' narrations and answers to interviews. The content-oriented approach to the study of social representations allows detecting objectified and shared contents of knowledge and can contribute to a preliminary understanding of trainee teachers' possible learning representations.

\subsection{An Overview of Recent Research on Pre-service Teachers}

Research on pre-service teachers' beliefs about children's learning is divided into two main branches.

The first branch is usually focused on learning theories and analyses of teachers' prior epistemological knowledge about teaching-learning processes. The second branch studies teachers' social representations of teaching-learning processes and aims at revealing teachers' naïve and common-sense theories on children's learning. Studies of both branches will be considered in this contribution to highlight the gaps in our knowledge of the field, which require further investigation. Nehls, König, Kaiser and Blömeke [23] stressed that preservice teachers' competence is influenced by their prior knowledge and allows distinguishing two distinct profiles: teachers with high levels of general pedagogical knowledge, markedly characterised by adaptivity and a constructivist vision of learning, and teachers with low levels of general pedagogical knowledge, characterised by weaker adaptivity. Schunk [30] focused on teachers' knowledge of Learning Theories and also on the way it is developed, considering preservice teachers' questions on the origin of learning and the teaching strategies usually adopted. Recent psychological studies on teacher's social representations of learning [13] highlight that pre-service teacher trainees' social representations pivot around constructivist theories.

Pre-service teachers' conception of learning is focused on the students' active role in the learning process and their teaching strategies are shaped by the idea of learning as connected to experience, research and problem-solving. However, these constructivist-oriented strategies are not intensively used due to time limitations and the high number of students per class. Few contributions focus on teachers' representations of the affective dimension learning. Naude, van den Bergh and Kruger [10] explored this aspect via focus groups and individual interviews with students enrolled in an academic facilitation programme pursuing collaborative and experience-based learning. The pre-service teachers interviewed stated that a learning environment evoking positive emotions increases personal involvement, broadens thought processes and actions, and fosters behavioural change. Other 
studies on teachers' social representations of learning focused on the differences between groups (teachers and students; teachers and parents). Martikainen [32] emphasised the varied social representations of teachership among teachers and students. Vasquez and Bochaca [14] stressed the different representations of the family-school relationship among future teachers. Few studies, however, tackle the social representations of children's learning in primary school pre-service teachers and kindergarten teachers.

\subsection{Aims}

The objective of this study is to analyse the main representations of children's learning in a pre-service group of teachers to verify how their implicit theories differ from scientific theories. A further goal is to observe the potential contrasting representations between primary school teachers and kindergarten teachers.

\section{METHODS}

The beliefs of a group of pre-service teachers about children's learning have been analysed at the beginning of a training course. We have extended Schunk's questions [30] as follows:

(1) What are the origins of learning?

(2) What are the psychological processes involved in learning?

(3) What are the learning theories that inspire you?

(4) What is the focus of learning?

We subsequently analysed the teachers' replies through a qualitative and quantitative study, examining teachers' lexicon and recording the underlying concepts.

The replies were evaluated by two independent raters, using the Cohen Kappa coefficient. The differences between the categories were analysed using the $\chi^{2}$ test.

\subsection{Participants}

The participants were 100 Italian pre-service teachers enrolled in a training course for teachers in infant and primary education at the University of Cagliari (Italy). 97\% of preservice teachers were female and the remaining $3 \%$ were male. The participants were training in infant education: $50 \%$ in primary school and 50\% in kindergartens.

$50 \%$ of teachers had a high school diploma in education, thus qualifying for school teaching with children, and had previous experiences as a primary school teacher or for kindergartens. The study was conducted according to the APA guidelines for ethical research in psychology.

\subsection{Procedure}

The approach is content-oriented, focused on objectified contents of knowledge. The approach aims at contributing to preliminary knowledge of the possible representations of learning among the interviewees.

The teachers' replies to the questions were ascribed to the following categories:
(1) Origins of learning (nature, culture, other aspects);

(2) Psychological aspects considered (cognition, behaviour, cultural aspects, experience, intelligence, emotion, motivation, other aspects);

(3) Underlying theories of reference (behaviourist, cognitive, classic Piagetian, socio-cultural, mixed concepts, other aspects);

(4) Focus on learning (teacher, pupil and other aspects).

The assignment to one of the above-mentioned categories was determined using the calculation of the percentage agreement and the Cohen Kappa coefficient, taking into account the evaluation of two independent raters. The percentage agreement is calculated using the formula: those in agreement/(agreement + disagreement) $* 100$.

The Cohen Kappa coefficient allows the calculation of the agreement rate between adjudicators to ensure objectivity.

The estimate for the Kappa coefficient is (Po-Pc)/(1-Pc), where $\mathrm{Po}_{\mathrm{o}}$ 'Observed proportion of agreement' and $\mathrm{Pc}=$ 'Proportion of agreement expected by chance'. The difference between the categories is analysed using the $\chi^{2}$ test $(\alpha .<0.05)$, which verifies if the frequency of a determinant distribution is significant or random.

\subsection{Response Categories}

Text categories were critically formed by two independent raters, taking into account the constant comparative method and comprehensive data treatment [33]. The problem of reliability was resolved using a digital recorder to allow file reproduction and access to interview transcriptions [34]. The text interpretation followed a cyclical process: after a first reading came the construction of the categories associated with words or short sentences taken from narrative text. The specific macro-categories considered are described below.

- The 'origins of learning' dimension emphasizes the following aspects: 'nature', referring to the biological dimension of learning and mental structures, and therefore indicating the genetic propensity of the individual to learn. 'Culture' concentrates on the external stimuli such as environmental, cultural and interpersonal relationships that aid the learning processes.

- The 'emphasised psychological aspects' dimension focuses on the subjective dimensions in defining learning, largely quoted by the interviewees: cognition, behaviour, cultural aspects, experience, intelligence, emotion and motivation.

- The 'underlying theories of reference' dimension attempts to evaluate the theoretical origins of the definition of learning given by the teachers: they could derive from a behaviourist, cognitive, classic Piagetian or socio-cultural theory, or even from a mixed theoretical framework.

- The 'focus on learning' dimension concentrates on the subjects involved in the process of learning: pupils who learn or teachers who teach. 


\section{RESULTS}

The descriptive results are reported in the following paragraphs.

\subsection{Origins of Learning}

$67 \%$ of the pre-service teachers interviewed consider learning as an acquisition of knowledge culture.

Only $6 \%$ refer to the internal biological factors or in-born factors; $11 \%$ view learning as a result of both internal and external factors to the individual; $16 \%$ returned answers which are not classifiable according to the criteria adopted $\left(\chi^{2}\right.$ $=96.080 ; \mathrm{df}=3 ; \mathrm{p}<.05)$.

Some of the spontaneous definitions given by teachers which fall into the 'culture' category include:

- "Learning is what children are able to perceive through the culture and the use of instruments we put at their disposal";

- "By learning we mean the acquisition of knowledge from culture".

Some examples of spontaneous definitions given by teachers which fall into the 'nature' category are:

- 'Learning varies according to the students' nature and capacity";

- "Learning is what is acquired over a period of years and depends on the child's mental development".

\subsection{Psychological Aspects Emphasized}

In considering the psychological aspects of learning, $49 \%$ of pre-service teachers refer to cognition; $13 \%$ refer to behaviour; $6 \%$ mention cultural aspects and only $3 \%$ consider emotions and motivation as fundamental factors in the learning process. Six percent of the interviewees emphasise several of the mentioned aspects (included experience and intelligence). Seven percent refer to none of the above-mentioned aspects and (sixteen) $16 \%$ propose other answers not included in the considered criteria $\left(\chi^{2}=106.02 ; \mathrm{df}=6 ; \mathrm{p}<.05\right)$. Some of the examples given by teachers which emphasize cognitive and behavioural aspects are:

- "Children learn when they acquire new information and arrive at their own cognition and concepts";

- "We can see children have learnt when they manifest new behaviour and know how to do things they did not know previously."

Examples of definitions referring to aspects of culture and experience are:

- "To learn means to enrich your own culture";

- "You learn from your own mistakes and experience";

- "You are constantly learning thanks to experience and the relationship with others".

Finally, examples of definitions emphasizing the importance of the emotional and motivational aspects of learning are:

- "It is possible to help children to learn, taking into account their motivation and emotions they feel while learning";

- "Often children who are de-motivated at school are children whose emotions are not understood".

\subsection{Teachers' Theories About Children's Learning}

The majority of the pre-service teachers interviewed (38\%) seem to have a personal underlying theory on the nature of cognitive learning which considers learning as being essentially "transfer of information". Fifteen percent (15\%) of teachers seem to embrace the behavioural type of theory, according to which learning is understood as a "modification in behaviour". Fourteen percent (14\%) of educators seem inspired by Piaget's theory of learning as a process of structural cognisance tied to specific stages of development. Thirteen percent $(13 \%)$ of the answers are shaped by the socio-cultural theory and only $4 \%$ are influenced by mixed concepts or current theories. Finally, 16\% of the answers are considered as unclassifiable $\left(\chi^{2}=38,36 ; \mathrm{df}=5 ; \mathrm{p}<0.05\right)$. Most definitions given by the teachers interviewed, therefore, can be brought back to the cognitive framework, as demonstrated by the following statements:

- "Learning is when new information is acquired";

- "Learning is first and foremost learning knowledge and new content".

"Cognitive" teachers emphasize how the learning process is guided by the acquisition of knowledge that must be worked out by children. They point out that, above all, it is necessary to be able to codify, store and remember information. With reference to the behaviourist view, we quote definitions such as:

- "Learning depends on the stimuli and reinforcement given";

- "Learning is favoured by the teacher who motivates children's capability development through the use of praise and recognition".

The Piagetian and structural approach subordinates learning to the phase of development in which the child is at a specific moment. Definitions consistent with this approach are:

- "Learning takes place when there is, on the child's part, the capacity to undertake specific activities linked with their stage of development".

Teachers who favour the socio-cultural point of view on learning assign significance to the socio-cultural context of reference and cultural artefacts, as evident in definitions such as:

- "Learning derives from culture and the use of tools, such as books, film, films, lessons, that aid learning". 


\subsection{Focus on Learning}

According to $65 \%$ of pre-service teachers, learning is a process that involves the pupil solely. Only $13 \%$ consider learning as a process involving both teacher and pupil, $6 \%$ focus only on teachers, while $16 \%$ report responses not being classifiable according to the criteria considered $\left(\chi^{2}=85.121\right.$; df $=3 ; \mathrm{p}<0.05)$.

\subsection{Differences Between Primary School Teachers and Kindergarten Teachers}

The majority of the primary school teachers interviewed (40\%) see learning as 'construction of knowledge' and acknowledges the student's active role in the learning process, thus revealing a constructivist conception of learning. Thirtyseven percent $(37 \%)$ see learning as mere 'transfer of information', linked to the cognitivist vision on learning. Thirteen percent (13\%) see learning as 'behaviour modification', linking the various definitions to the behavioural perspective (according to which learning is the result of responses to environmental stimuli). Three percent (3\%) connect learning mainly to the student's socio-cultural context and $7 \%$ have to be included in the 'Other' category, for which the answers were either missing, too vague or impossible to relate to a specific theory.

Most kindergarten teachers (34\%), like primary school teachers, share a constructivist perspective on learning. Twenty-eight percent $(28 \%)$ relate learning to stimulusresponse behaviour; $21 \%$ define learning in cognitive terms, as the transfer of information.; $4 \%$ relate learning mainly to the socio-cultural context; $2 \%$ mention children's emotions and the remaining $11 \%$ have to be included in the 'other' category.

\section{DISCUSSION}

The teachers interviewed attribute the origins of learning to essentially cognitive and cultural factors. The reference to emotions is rare. Learning is predominantly understood as 'construction of knowledge' by both primary school teachers and kindergarten teachers. For the former, learning is also 'transfer of information', while the latter see learning as 'behaviour modification'. This result is consistent with previously published literature [31, 23, 13], highlighting that teachers' training is mainly constructivist and anchored in specific cultural models. However, the cognitivist perspective on learning, pivoting on the notion of transfer of information, prevails among primary school teachers, whereas the behavioural perspective on learning, seen as behaviour modification, prevails among kindergarten teachers. Both groups of pre-service teachers probably embraced the representations of learning traditionally rooted in the type of school in which they would like to work: the kindergarten teacher modifies behaviour, while the primary school teacher 'teaches notions'.

The lack of reference to emotive and motivational aspects of learning is quite striking, in particular among primary teachers, who never referred to emotions in their definitions of learning. Many teachers probably consider motivational aspects of learning to be fundamental when devising strategies and techniques in their own teaching and practical application.
However, when invited to provide spontaneous definitions about learning, teachers feel the effect of previous cultural training, employ a terminology centered on old cultural models, and cannot fully express the importance of motivational aspects of learning. How can a proper integration between teacher's implicit theories and disciplinary theories in educational psychology be facilitated? At the level of training, it would be useful to encourage the self-understanding of implicit theories on learning in pre-service teachers, to help them understand how their personal models may influence their educational choices. The various methods for understanding learning bring us back to both constructions elaborated by the scientific community and transmitted through learning and common-sense theories shared within the group and the teacher community.

\section{CONCLUSION}

The analysis of social representations within the teachers interviewed could enable the recognition and the understanding of the mechanisms which stabilize the social representation over time, thus facilitating the analysis of the learning process anchored in scientific-oriented definitions.

If teachers' contents emerging from their implicit theories are made explicit, the beliefs which may impede learning can be detected via a contribution to the reflection on the construction and reconstruction of knowledge.

Finally, promoting awareness and reflection during training, by merging research and practice, can facilitate the acknowledgement of the processes underlying the social construction of knowledge and the mechanisms which ease positive relations within school contexts [31, 35 - 38].

The training of the pre-service teachers interviewed could be implemented with a mindfulness training program to increase the awareness of their implicit beliefs and the importance of emotions in the teaching-learning process. A growing body of research, in fact, emphasizes the benefits of mindfulness in pre-service teachers [39, 40]: mindfulness practices can enhance teachers' skills and knowledge of psychological processes. In conclusion, the present pilot study was useful to understand the implicit theories of the pre-service teachers in the sample considered and to hypothesize some future training courses.

The main limitation of this study concerns the use of external pre-built categories, which could be solved by a textual analysis of the interviews. Such conversation analysis could improve the knowledge of the most frequently naming processes [16] used by teachers, detecting which terms refer to static representations and naïve theories of reference.

\section{ETHICS APPROVAL AND CONSENT TO PARTI- CIPATE}

The study was approved by the Ethics Committee of the Cagliari University, Cagliari, Italy under approval no. UniCa Prot. n 0040431.

\section{HUMAN AND ANIMAL RIGHTS}

No Animals were used in this research. All human research 
procedures followed were in accordance with the ethical standards of the committee responsible for human experimentation (institutional and national), and with the Helsinki Declaration of 1975, as revised in 2013.

\section{CONSENT FOR PUBLICATION} teacher.

We obtained the written informed consent from each

\section{AVAILABILITY OF DATA AND MATERIALS}

Not applicable.

\section{FUNDING}

None.

\section{CONFLICT OF INTEREST}

The authors reported no potential conflict of interest.

\section{ACKNOWLEDGEMENTS}

Declared none.

\section{REFERENCES}

[1] Clement M. Reducing the stress of student teaching. Contemp Educ 1999; 70: 20-6.

[2] Gold P, Bachelor P. Signs of burnout are evident for practice during the teachers'. Training Period Education 2001; 108: 546-55.

[3] Drechsel B, Breuning K, Thurn D, et al. Learning to teach reading: A theory-practice approach to psychology teaching in university teacher education. Psychol Learn Teach 2014; 13: 250-9.

[http://dx.doi.org/10.2304/plat.2014.13.3.250]

[4] Nonnis M, Massidda D, Cuccu S, et al. The impact of workaholism on nurses' burnout and disillusion. Open Psychol J 2018; 11: 77-88. [http://dx.doi.org/10.2174/1874350101811010077]

[5] Pedditzi ML, Nonnis M. Psycho-social sources of stress and burnout in schools: research on a sample of Italian teachers. Med Lav 2014; 105(1): 48-62. [PMID: 24552094]

[6] Luisa PM. Work-family interface, work relations and burnout in school teachers: A study on a group of subjects from italian primary schools.Handbook on burnout and sleep deprivation: risk factors, management strategies and impact on performance and behavior. https://www.novapublishers.com/catalog/product_info.php?products_i $\mathrm{d}=53210$ New York: Nova Science Publishers 2015; pp. 147-61.

[7] Anning A. Teachers' theories about children's learning.Teachers' professional learning. London: Farmer Press 1988; pp. 128-44.

[8] Calderhead J. Teachers: Beliefs and Knowledge.Handbook of Educational Psychology. New York: MacMillan 1988; pp. 88-101.

[9] Putnam RT, Borko H. Teacher Learning: Implications of New Views of Cognition.International Handbook of Teachers and Teaching. Dordrecht: Kluwer 1997; pp. 21-36

[http://dx.doi.org/10.1007/978-94-011-4942-6_30]

[10] Naude L, van den Bergh TJ, Kruger IS. "Learning to like learning": An appreciative inquiry into emotions in education. Soc Psychol Educ 2014; 17: 211-28.

[http://dx.doi.org/10.1007/s11218-014-9247-9]

[11] Karlen Y, Compagnoni M. Implicit theory of writing ability: Relationship to metacognitive strategy knowledge and strategy use in academic writing. Psychol Learn Teach 2017; 16: 47-63.

[http://dx.doi.org/10.1177/1475725716682887]

[12] Overton D. Findings and implications of the relationship of pre-service educators, their university tutor and in-service teachers regarding professional development in science in the primary school system. Prof Dev Educ 2018; 44: 595-606.

[http://dx.doi.org/10.1080/19415257.2017.1388268]

[13] Jančič P, Hus V. Representation of teaching strategies based on constructivism in social studies. Int J Innov Learn 2019; 25(1): 64-77. [http://dx.doi.org/10.1504/IJIL.2019.096535]
[14] Vásquez H, Bochaca J. Social representation of family-school relationship from initial teacher training. Rev Electrón Investig Educ 2020; 22(1): 1-14

[15] Pérez-Tello S, Antonietti A, Liverta Sempio O. Che cos'è l'apprendimento? Le concezioni degli student. Roma: Carocci 2005.

[16] Moscovici S. The Phenomenon of Social Representations.Social Representations. Cambridge: Cambridge University 1984

[17] Moscovici S. La psychanalise, son image et son public. Paris: PUF 1961.

[18] Jodelet D. Madness \& Social Representations. London: Harvester Wheatsheaf 1991

[19] Mugny G, Carugati F. L'intelligence au pluriel Fribourg: Cousset. 1985.

[20] Emiliani F, Molinari L. Mothers' social representations of their children's learning and development. Int J Educ Res 1989; 13: 657-70. [http://dx.doi.org/10.1016/0883-0355(89)90048-7]

[21] Pedditzi ML, Rollo D. Attachment in nursery schools: The teachers have a monotropic or polyadic view? Psicol Clin Sviluppo 2014; 18(1): 143-51.

[22] Pedditzi ML. Representations of bullying between teachers and social workers. does a traditional vision of the phenomenon persist? Psicol Clin Sviluppo 2020; 24(1): 139-51.

[23] Nehls C, König J, Kaiser G, et al. Pro les of teachers' general pedagogical knowledge: nature, causes and e ects on beliefs and instructional quality. ZDM Math Educ 2019; 52(2): 343-57. [http://dx.doi.org/10.1007/s11858-019-01102-3]

[24] Ertmer PA, Newby TJ. Behaviorism, cognitivism, constructivism: Comparing critical features from an instructional design perspective. Perform Improv Q 2013; 26: 43-71. [http://dx.doi.org/10.1002/piq.21143]

[25] Lave J, Wenger D. Situated Learning Legitimate Peripheral Participation. Cambridge: Harvard University Press 1991. [http://dx.doi.org/10.1017/CBO9780511815355]

[26] Duveen G, Lloyd B. Social representations and the development of knowledge. London: Cambridge University Press 1990. [http://dx.doi.org/10.1017/CBO9780511659874]

[27] Molinari L, Emiliani F. More on the structure of social representations: Central core and social dynamics. Pap Soc Represent 1996; 5: 41-50.

[28] Glaser R, Bassok M. Learning theory and the study of instruction. Annu Rev Psychol 1989; 40: 631-66.

[http://dx.doi.org/10.1146/annurev.ps.40.020189.003215]

[29] Bransford J, Vye N, Stevens R, et al. Learning theories and education: Toward a decade of synergy.Handbook of Educational Psychology. Mahwah, NJ: Erlbaum 2005; pp. 1-95.

[30] Schunk DH. Learning Theories: An Educational Perspective. New York: Pearson 2012

[31] Antonietti A, Grimes PW, Rogers KE. Learning: What teachers think about. Scuola Italiana Moderna 1997; 105: 10-1.

[32] Martikainen J. Social representations of teachership based on students' and teachers' drawings of a typical teacher. Soc Psychol Educ 2019, 22(3): 579-606.

[http://dx.doi.org/10.1007/s11218-019-09490-w]

[33] Silverman D. Doing qualitative research: A pratical Handbook. London: Sage 2000

[34] Miles BM, Huberman AM. Analyse des données qualitatives. Paris: De Boeck 2003.

[35] Palmonari A, Emiliani F. Psicologia delle Rappresentazioni Sociali Teoria e applicazioni. Bologna: Il Mulino 2014.

[36] Pedditzi ML, Nonnis M, Massidda D. Social competence and students' satisfaction in school transitions: A research in secondary schools. Psicologia della Salute 2016; 2: 43-62.

[37] Pedditzi ML, Marcello P. School Social Context, Students' SelfEfficacy and Satisfaction in High School. Open Psychol J 2018; 11(1): 249-60.

[http://dx.doi.org/10.2174/1874350101811010249]

[38] Pedditzi ML, Lucarelli L. Bullying and depressive risk: An exploratory survey in a sample of students in early adolescence. Medico e Bambino 2014; 33(8): 533-4

[39] Kerr SL, Lucas LJ, Di Domenico GE, et al. Is mindfulness training useful for pre-service teachers? An exploratory investigation. Teach Educ 2017; 28: 349-59.

[http://dx.doi.org/10.1080/10476210.2017.1296831]

[40] Gross JJ. The emerging field of emotion regulation: An integrative review. Rev Gen Psychol 1998; 2: 271-99.

[http://dx.doi.org/10.1037/1089-2680.2.3.271] 